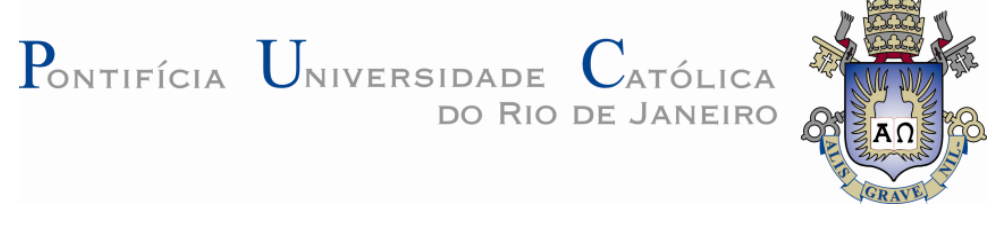

Filipe Pollis de Carvalho

Ser Carbono Eficiente Implica em Maior Rentabilidade no Brasil?

Dissertação apresentada ao Programa de PósGraduação em Administração de Empresas da PUCRio como requisito parcial para obtenção do título de mestre em Administração de Empresas.

Orientador: Prof. Antonio Carlos Figueiredo Pinto

Rio de Janeiro

Dezembro de 2015 


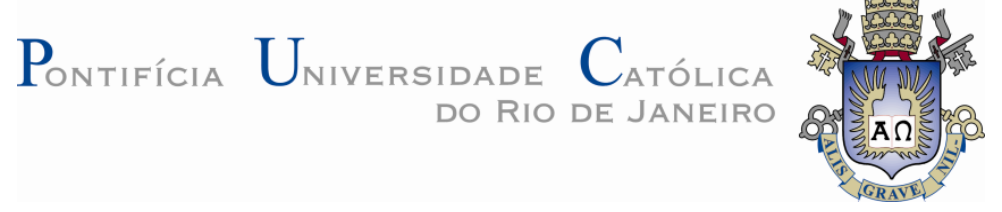

Filipe Pollis de Carvalho

\title{
Ser Carbono Eficiente Implica em Maior Rentabilidade no Brasil?
}

Dissertação apresentada como requisito parcial para obtenção do grau de Mestre pelo Programa de PósGraduação em Administração de Empresas da PUCRio. Aprovada pela Comissão Examinadora abaixo assinada.

\author{
Prof. Antonio Carlos Figueiredo \\ Orientador \\ Departamento de Administração- PUC-Rio \\ Prof. Marcelo Cabús KIötzle \\ Departamento de Administração - PUC-Rio
}

Prof. Luiz Felipe Jacques da Motta

Departamento de Administração - PUC-Rio

Prof. Marco Antonio Cunha de Oliveira

UFRJ

Prof a . Mônica Herz

Vice-Decana de Pós-Graduação do CCS - PUC-Rio

Rio de Janeiro, 16 de dezembro de2015 
Todos os direitos reservados. É proibida a reprodução total ou parcial do trabalho sem autorização da universidade, do autor e do orientador.

Filipe Pollis de Carvalho

Graduado em Administração pela Universidade Federal do Rio de Janeiro (UFRJ), 2013.

Ficha Catalográfica

\begin{tabular}{|l}
\hline Carvalho, Filipe Pollis de \\
Ser Carbono Eficiente Implica em Maior \\
Rentabilidade no Brasil? / Filipe Pollis de Carvalho ; \\
orientador: Antonio Carlos Figueiredo. - 2015. \\
44 f. : il. (color.); $30 \mathrm{~cm}$ \\
Dissertação (mestrado)-Pontifícia Universidade \\
do Rio de Janeiro, Departamento de \\
Católica \\
Administração, 2015. \\
Inclui bibliografia \\
1. Administração - Teses. 2. Sustentabilidade.3. \\
Rentabilidade.4. ICO2. I. Figueiredo,Antonio Carlos.II. \\
Pontifícia Universidade Católica do Rio de Janeiro. \\
Departamento de Administração. III. Título.
\end{tabular}




\section{Agradecimentos}

Ao meu orientador Professor Antonio Carlos Figueiredo Pinto pelo estímulo e parceria para a realização desse trabalho.

À Capes e à PUC-Rio, pelos auxílios concedidos, sem os quais este trabalho não poderia ser realizado.

Ao meu amigo José Felipe, grande incentivador para a minha inscrição no curso.

Ao meu amigo Vinícius por todo apoio, paciência e compreensão.

Aos meus pais Carlos e Rosane, pela educação, atenção e carinho de todas as horas.

À Verônica, pelo companheirismo e apoio.

A todos os professores e funcionários do IAG pelos ensinamentos e pela ajuda.

A todos os amigos e familiares que de uma forma ou de outra me estimularam ou me ajudaram. 


\section{Resumo}

Carvalho, Filipe Pollis de; Pinto, Antonio Carlos Figueiredo. Ser Carbono Eficiente Implica em Maior Rentabilidade no Brasil? Rio de Janeiro, 2015. 44p. MSc. Dissertação - Departamento de Administração, Pontifícia Universidade Católica do Rio de Janeiro.

Esta pesquisa analisou os possíveis impactos na rentabilidade de empresas que ingressaram ou saíram do Índice de Carbono Eficiente (ICO2). Buscou-se compreender se a participação de uma empresa nesta carteira beneficiaria o seu acionista com ganhos de rentabilidade e, caso contrário, se a saída implicaria em queda na rentabilidade. Até então, o único estudo com tal propósito realizado para o ICO2 foi baseado na primeira carteira formada e verificou apenas o movimento de entrada. Assim, este trabalho procurou analisar este índice sob uma ótica mais dinâmica e atualizada, a partir de mudanças na sua composição ao longo do tempo. Para alcançar este objetivo, realizou-se um estudo de eventos a fim de identificar a existência de retornos anormais em empresas que entraram e saíram do ICO2. A amostra analisada compreendeu doze empresas que realizaram o movimento de entrada ou saída ao longo do período de 2012 a 2015. Os resultados proporcionaram um avanço no entendimento acerca de investimentos sustentáveis no Brasil, uma vez que foram detectados casos de retornos anormais positivos e significantes ao ingressar no ICO2. Ademais, houve caso de retorno anormal negativo e significantes ao deixar o ICO2. Logo, levanta-se a possibilidade de investidores brasileiros valorizarem mais determinadas ações de empresas que adotam práticas carbono eficientes em seu modelo de negócios.

\section{Palavras-chave}

Sustentabilidade; Rentabilidade; ICO2. 


\section{Abstract}

Carvalho, Filipe Pollis de; Pinto, Antonio Carlos Figueiredo (Advisor). Be Carbon Efficient Implies Greater Profitability in Brazil? Rio de Janeiro, 2015. 44p. MSc. Dissertation - Departamento de Administração, Pontifícia Universidade Católica do Rio de Janeiro.

This research examined the possible impact on the profitability of companies who entered or left the Carbon Efficient Index (ICO2). It sought to understand whether the participation of a company in this portfolio would benefit its shareholders with profitability gains and otherwise, if the output would fall in profitability. Until then, the only study for that purpose held for ICO2 was formed based on the first book and only checked the input movement. This work tried to analyze this index in a more dynamic optics and updated from changes in its composition over time. To accomplish this, there was an event study to identify the existence of abnormal returns in companies in and out of ICO2. The sample comprised twelve companies that made the entry or exit of movement throughout the period 2012 to 2015. The results provide a breakthrough in the understanding of sustainable investments in Brazil, as they have been detected cases of positive abnormal returns and significant at joining ICO2. Moreover, there was the case of negative abnormal return and significant to leave the ICO2. Hence arises the possibility of Brazilian investors to value more certain stocks of companies that adopt efficient carbon practices in their business model.

\section{Keywords}

Sustainability; profitability; ICO2. 


\section{Sumário}

1 Introdução 10

2 Referencial Teórico 13

2.1 Responsabilidade Social Corporativa (RSC) 13

2.2 Investimentos Socialmente Responsáveis (ISR) 15

2.3 Pesquisas sobre ISR no Mundo 20

2.4 Pesquisas sobre ISR no Brasil 21

2.5 Retorno Anormal $\quad 24$

2.5.1 Modelos Estatísticos 24

2.5.2 Modelos Econômicos $\quad 25$

3 Metodologia 27

3.1 Definição do Evento e Seleção da Amostra 28

3.2 Linha do Tempo do Evento 30

3.3 Retornos Teórico, Anormal e Acumulado 31

3.4 Teste de Hipótese 32

4 Resultados $\quad 34$

4.1 Estatística Descritiva

4.2 Estudo de Eventos $\quad 35$

$\begin{array}{ll}5 \text { Conclusão } & 39\end{array}$

6 Referências $\quad 41$ 


\section{Lista de Figuras}

Figura 1: Volatilidade do ICO2 …..................................................... 19

Figura 2: Etapas do estudo de eventos ............................................. 28

Figura 3: Linha do tempo do estudo de eventos ................................30 


\section{Lista de Tabelas}

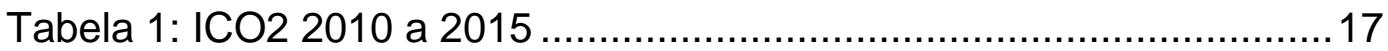

Tabela 2: Setores presentes no ICO2 em $2015 \ldots \ldots \ldots \ldots \ldots \ldots \ldots \ldots \ldots \ldots \ldots \ldots . . . .18$

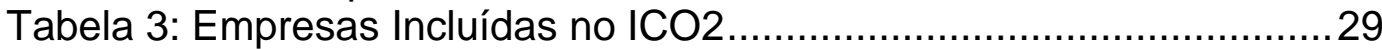

Tabela 4: Empresas Excluídas do ICO2 …..........................................30

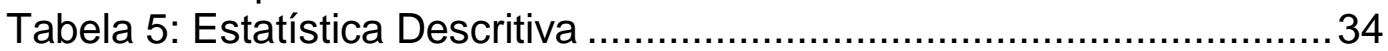

Tabela 6: Empresas Ingressantes no ICO2 ..........................................36

Tabela 7: Empresas Excluídas no ICO2 (1) ............................................37

Tabela 8: Empresas Excluídas no ICO2 (2) .........................................38 


\section{1 \\ Introdução}

No âmbito organizacional, percebe-se que a relevância das questões éticas e ambientais é crescente com o decorrer dos anos. Hoje em dia, não basta apenas que uma organização cumpra suas responsabilidades econômicas e legais, mas também é necessário considerar compromissos éticos, morais e sociais. (ASHLEY, 2010).

A partir da vinculação entre desenvolvimento e meio ambiente surge o conceito de desenvolvimento sustentável, que, de acordo com Barbieri (2011), significa atender às necessidades do presente sem prejudicar as gerações futuras no atendimento de suas necessidades. Sendo assim, os recursos naturais devem ser utilizados de maneira responsável e consciente.

Sob a ótica cronológica, um dos marcos do avanço da discussão da sustentabilidade foi a ocorrência da Conferência das Nações Unidas para o Meio Ambiente e o Desenvolvimento (CNUMAD), realizada na cidade do Rio de Janeiro em 1992. Deste encontro resultou a Agenda 21, um programa de ações que tinha como objetivo promover um novo padrão de desenvolvimento global, que englobasse proteção ambiental, justiça social e eficiência econômica (UNITED NATIONS, 1992).

Já em 1997, houve a assinatura por parte de diversos países do Protocolo de Quioto, segundo o qual as nações industrializadas reduziriam suas emissões combinadas de gases de efeito estufa em pelo menos 5\% em relação aos níveis de 1990, com prazo até 2012. Este compromisso foi uma tentativa de reverter o crescimento contínuo de emissões verificado há mais de um século (MINISTÉRIO DA CIÊNCIA E TECNOLOGIA, 2015).

De acordo com Macedo et al. (2012), os atuais sinais de degradação do meio ambiente mostram que a responsabilidade em torno do tema não pode abranger apenas a esfera pública, mas a sociedade de maneira geral. Pautada na importância do engajamento social com o tema da sustentabilidade, a BM\&F 
Bovespa e o Banco Nacional de Desenvolvimento Econômico e Social (BNDES) criaram em 2010 o Índice de Carbono Eficiente (ICO2), que tem o objetivo de evidenciar empresas que prezam pela transparência com relação à emissão de gases de efeito estufa (GEE).

O ICO2 foi o segundo índice de sustentabilidade criado oficialmente pela bolsa de valores brasileira, sendo o primeiro o Índice de Sustentabilidade Empresarial (ISE). Segundo a BM\&FBOVESPA (2015), o ICO2 é composto por empresas participantes do índice IBrX-50 (conjunto das cinquenta ações de maior liquidez da BM\&F Bovespa) que aceitaram, voluntariamente, participar deste esforço de atuar em uma economia de "baixo carbono".

Desta forma, o ICO2 busca evidenciar aspectos empresariais que vão além do retorno financeiro no curto prazo, a partir do desenvolvimento de um ambiente de negócios alinhado com as demandas da sociedade. Em suma, buscase evidenciar empresas que estão engajadas nas questões das mudanças climáticas.

Provavelmente devido ao pouco tempo decorrido desde o lançamento do ICO2, ainda não foram identificados muitos trabalhos acerca deste tema. Os principais estudos verificados foram os de Cazzari e Lima (2012), Barbosa et al. (2013), Reis, Moreira e França (2013) e Viviani et al. (2014). Neste sentido, este trabalho busca avançar neste campo do conhecimento ainda com poucas pesquisas acadêmicas.

Especificamente, o presente estudo busca avançar no conhecimento acerca do ICO2 ao tentar responder a seguinte pergunta: "O fato de uma empresa entrar ou sair do Índice de Carbono Eficiente acarretaria em mudanças no seu nível de rentabilidade?"

O principal motivador desta indagação foi o trabalho de Barbosa et al. (2013). A partir da primeira carteira do ICO2 - 2010 - foi feita uma análise de eventos para detectar se houve mudança na rentabilidade das empresas ingressantes. A conclusão foi a ausência de impacto no retorno das ações das empresas após o anúncio de ingresso no índice. Em termos matemáticos, não foi possível rejeitar a hipótese nula de que os retornos não são afetados pelo ingresso no índice. 
A busca por variações de rentabilidade após a entrada ou saída de uma empresa do ICO2 foi captada a partir de um estudo de eventos, em que há a tentativa de identificar retornos anormais de determinadas empresas. A delimitação temporal deste trabalho foi o período compreendido entre 2012 e 2015 , em que se totalizou 4 entrantes e 8 retirantes.

Os resultados mostraram que, dentre as empresas ingressantes no ICO2, todos os retornos anormais significativos foram positivos. Já dentre aquelas que deixaram o ICO2, houve casos de retornos anormais significativos negativos. Desta forma, surgiu a possibilidade de a participação no ICO2 ser impactante na rentabilidade das organizações.

Quanto à organização do texto, o capítulo 2 aborda o referencial teórico acerca dos investimentos socialmente responsáveis (ISR) e das pesquisas já publicadas sobre o tema. O capítulo 3 contempla a metodologia utilizada para analisar os dados. Em seguida, o capítulo 4 expõe os resultados obtidos e, finalmente, o capítulo 5 apresenta as conclusões e as propostas de pesquisas futuras. 


\section{2 \\ Referencial Teórico}

Este capítulo está divido em cinco partes. A primeira aborda o tema da responsabilidade social corporativa e sua evolução ao longo do tempo. Já a segunda trata dos investimentos socialmente responsáveis. A terceira e a quarta seção tratam de pesquisas brasileiras e internacionais sobre o tema. Por fim, são apresentados modelos de cálculo de retornos anormais.

\section{1 \\ Responsabilidade Social Corporativa (RSC)}

A ponderação dos impactos ambientais e sociais das ações individuais e organizacionais não é fato exclusivo do século XXI. A partir da década de 1970, surgiram diversos estudos na área de negócios que buscavam debater se o foco das ações organizacionais deveria ser atender estritamente a objetivos econômicos (CARROL, 1991; FRIEDMAN, 1970; FREEMAN,1984).

Primeiramente, identifica-se uma abordagem organizacional mais simples e objetiva: a teoria dos shareholders. A partir desta ótica, Friedman (1970) publicou um trabalho cujo título resume sua tese central: "A responsabilidade social de um negócio é aumentar seus lucros". Este artigo defende que o maior interesse das organizações é maximizar o lucro dos seus proprietários ou, dependendo de sua estrutura de controle, acionistas.

Segundo este autor, apenas pessoas físicas podem assumir responsabilidades, enquanto as organizações não poderiam ter tal atribuição. A função principal de um gestor deveria ser gerar o máximo de dinheiro possível do negócio para seus proprietários, respeitando as obrigações legais e os costumes éticos.

Alguns anos após o surgimento da teoria dos shareholders, é definido na Conferência das Nações Unidas para o Meio Ambiente e o Desenvolvimento 
(CNUMAD) o conceito de desenvolvimento sustentável. A ideia lançada foi de que o atendimento das necessidades presentes da sociedade não deveria prejudicar as gerações futuras no atendimento de suas necessidades.

Alinhada à definição de desenvolvimento sustentável, a teoria dos stakeholders ampliou o escopo dos objetivos organizacionais. De acordo com Freeman (1984), as organizações deveriam atender a todas as partes interessadas diretamente ou não no negócio, além dos seus proprietários. O objetivo de maximização de lucros deve ser compatibilizado com outras demandas sociais.

Tais demandas da sociedade complementam o objetivo primário de um negócio que é o lucro. De acordo com Carroll (1991), as responsabilidades organizacionais podem ser agrupadas em:

a) Responsabilidades econômicas: obter lucratividade.

b) Responsabilidades legais: obedecer às leis.

c) Responsabilidades éticas: fazer o que é justo, certo.

d) Responsabilidades filantrópicas: contribuir para a qualidade de vida da sociedade.

Em outras palavras, as organizações devem buscar: promoção da equidade social, eficiência econômica e conservação ambiental (COHEN, 2004). Essas três dimensões são representadas pela palavra triple bottom line (NORMAN, MacDONALD, 2004).

De acordo com Wood (1991), o pilar da responsabilidade social corporativa (RSC) está na expectativa da sociedade em determinadas atitudes das empresas, já que são entidades com alguns interesses comuns. Desta forma, Frederick (1978) adota o termo responsividade social corporativa, que contempla a disposição das organizações em responder às demandas sociais.

Já no contexto brasileiro, a Constituição Federal de 1988 (CF/88) formalizou a importância da RSC para o país ao englobar capítulo exclusivo acerca do meio ambiente. Em 2003, foi aprovada a emenda constitucional $n^{\circ} 42$, responsável por incluir a defesa do meio ambiente como princípio geral da atividade econômica.

Em suma, a responsabilidade social corporativa evoluiu de uma simples ideia de maximização de lucro a uma visão mais ampla, que aborda os aspectos 
sociais, ambientais e econômicos. Ademais, os interesses do proprietário passaram a ser compatibilizados com os das demais partes interessadas no negócio.

\section{2 Investimentos Socialmente Responsáveis (ISR)}

Os investimentos socialmente responsáveis são aqueles baseados em critérios sociais, ambientais, éticos e/ou de governança na seleção e no gerenciamento do conjunto de ativos investidos (BM\&F BOVESPA, 2015).

Assim, a fim de atender à necessidade de evidenciação de questões socioambientais nas práticas organizacionais, os mercados de capitais de diversos países criaram índices que reúnem empresas alinhadas com este propósito.

O primeiro índice de sustentabilidade criado oficialmente no mundo foi o Dow Jones Sustainability Index (DJSI), em 1999. Este indicador aborda o desempenho de ações das melhores empresas do mundo em relação a critérios econômicos, ambientais e sociais. Todos os setores da indústria são contemplados. Em 2014, o DJSI global reunia 319 componentes (DJSI, 2015).

Já na América Latina, a BM\&F Bovespa foi a responsável por lançar em 2005 o primeiro índice que retrata as ações sustentáveis de empresas, o Índice de Sustentabilidade Empresarial (ISE). Seu objetivo é "[...]criar um ambiente de investimento compatível com as demandas de desenvolvimento sustentável da sociedade contemporânea e estimular a responsabilidade ética das corporações" (BM\&F BOVESPA, 2015).

Em termos financeiros, o ISE mede o retorno médio de uma carteira teórica de ações de empresas de capital aberto comprometidas com boas práticas de sustentabilidade. Assim, a bolsa de valores brasileira seguiu uma tendência mundial de evidenciar empresas que se preocupam com a sustentabilidade nas suas ações e geram mais valor para o acionista no longo prazo (TEIXEIRA, NOSSA e FUNCHAL, 2011).

Em 2010, surgiu o índice de carbono eficiente (ICO2), resultado de um esforço contínuo da BM\&F Bovespa e do Banco Nacional de Desenvolvimento Econômico e Social (BNDES) a fim de criar uma carteira teórica de ações de 
empresas que, voluntariamente, divulgam suas emissões de gases do efeito estufa (GEE).

Sendo assim, este é um incentivo para que as empresas adotem uma postura transparente em relação às suas práticas ambientais e atuem em uma economia de "baixo carbono". Este esforço está alinhado com a discussão acerca do aquecimento global e das mudanças climáticas (BM\&F BOVESPA, 2015).

Existem critérios que uma empresa deve atender, cumulativamente, para fazer parte da carteira do ICO2. São eles:

- Pertencer à carteira do IbrX 50 (índice que reúne as 50 ações de maior liquidez da BM\&F Bovespa);

- Ter aderido formalmente à iniciativa do ICO2;

- Reportar, anualmente, seu inventário de GEE;

Um dos parâmetros para montar a carteira do índice é o cálculo do coeficiente emissão / receita. Tal medida permite comparar empresas de portes diferentes e avaliar se a emissão de GEE pelas empresas é feita de maneira eficiente. A fórmula do coeficiente é:

$$
\text { Coeficiente emissão/receita } a_{t}=\frac{{\text { Emissão de } G E E_{t}}_{\text {Receita }}}{\text { R }}(1)
$$

Em que:

- Emissão de $G E E_{t}$ é a quantidade de toneladas de dióxido de carbono equivalente emitida no ano-base t.

- Receita $_{t}$ é a receita bruta apurada nas demonstrações financeiras padronizadas do ano-base $t$ em milhões de reais.

Por outro lado, há situações em que companhias podem ser excluídas do ICO2:

- Não atendimento de qualquer um dos critérios de inclusão acima mencionados;

- Serem listadas em situação especial (recuperação judicial ou extrajudicial, regime especial de administração temporária, intervenção ou qualquer outra hipótese definida pela Bolsa).

Percebe-se, assim, que a inclusão ou exclusão de um ativo da carteira não depende exclusivamente da vontade das empresas. Trata-se do alinhamento entre 
a companhia e o respeito à metodologia definida pela BM\&F Bovespa para a participação no índice.

Seguem algumas informações sobre a carteira do ICO2:

\begin{tabular}{|c|c|c|c|c|c|c|}
\hline ICO2 & $\mathbf{2 0 1 0}$ & $\mathbf{2 0 1 1}$ & $\mathbf{2 0 1 2}$ & $\mathbf{2 0 1 3}$ & $\mathbf{2 0 1 4}$ & $\mathbf{2 0 1 5}$ \\
\hline $\mathrm{N}^{\mathbf{0}}$ empresas & 42 & 40 & 35 & 35 & 29 & 29 \\
\hline $\begin{array}{c}\text { Valor de } \\
\text { mercado } \\
\text { médio (R\$ } \\
\text { bilhão) }\end{array}$ & 1.622 & 1.304 & 1.350 & 1.424 & 1.395 & 1.402 \\
\hline
\end{tabular}

Tabela 1: ICO2 2010 a 2015

Fonte: adaptada de BM\&F Bovespa

A tabela 1 revela que o $n^{\circ}$ de companhias presentes no ICO2 sofreu uma diminuição de, em média, 30\% desde a sua formação em 2010. O valor de mercado anual médio da carteira também foi reduzido de $\mathrm{R} \$ 1.662$ bilhões para $\mathrm{R} \$ 1.402$, o que representa uma queda de $15 \%$ do valor monetário. No período entre 2010 e 2015, a média do valor de mercado do índice é de $\mathrm{R} \$ 1.400$ bilhões. 
Os setores da economia presentes no ICO2 são os seguintes:

\begin{tabular}{|c|c|c|} 
ICO2 por setores (2015) & $\mathbf{N}^{\mathbf{0}}$ ações & Part. (\%) \\
\hline Alimentos processados & 2 & $10,64 \%$ \\
\hline Bebidas & 1 & $11,72 \%$ \\
\hline Comércio Distr. & 1 & $2,83 \%$ \\
\hline Fumo & 1 & $1,93 \%$ \\
\hline Produtos pessoais e & 1 & $1,43 \%$ \\
limpeza & & \\
\hline Construção e engenharia & 1 & $0,9 \%$ \\
Transporte & 2 & $3,00 \%$ \\
\hline Comércio & 2 & $2,82 \%$ \\
Imóveis & 1 & $1,38 \%$ \\
\hline Holdings & 2 & $5,15 \%$ \\
\hline Intermediação Financeira & 5 & $35,5 \%$ \\
\hline Serviços Financeiros & 2 & $7,01 \%$ \\
\hline Madeira e Papel & 3 & $2,52 \%$ \\
Mineração & 2 & $6,15 \%$ \\
\hline Química & 1 & $0,3 \%$ \\
\hline Telefonia Fixa & 3 & $2,93 \%$ \\
\hline Telefonia Móvel & 1 & $2,19 \%$ \\
\hline Energia Elétrica & 1 & $1,59 \%$ \\
\hline
\end{tabular}

Tabela 2: Setores presentes no ICO2 em 2015

Fonte: adaptada de BM\&F Bovespa

Quanto à sua composição, o ICO2 apresenta-se como uma carteira formada por quase 20 setores da economia. Entretanto, a distribuição relativa do valor monetário total entre tais setores revela que quase $50 \%$ do índice é vinculado a dois setores: alimentos processados e intermediação financeira. Logo, há indícios de que este índice é afetado por características de alguns setores ou empresas que o compõe. 
A respeito da dispersão dos retornos do índice, observa-se:

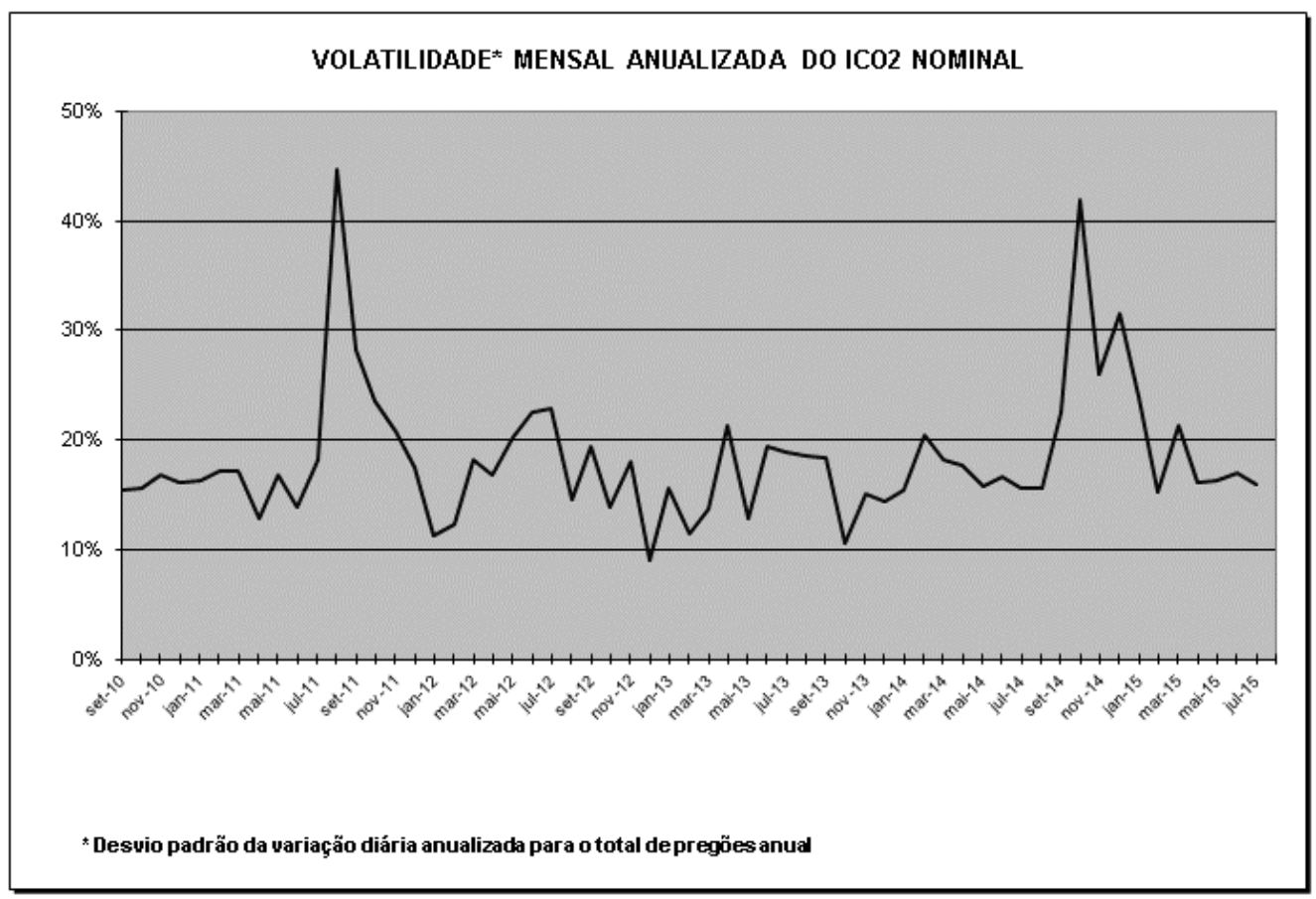

Figura 1: Volatilidade do ICO2

Fonte: adaptada de BM\&F Bovespa

A figura acima apresenta a volatilidade mensal anualizada do ICO2. A volatilidade de uma ação é uma medida de incerteza a respeito dos retornos de uma ação (HULL, 2008). Verifica-se que seu valor permaneceu, em boa parte da série, entre 10 e $20 \%$.

Observam-se dois picos de volatilidade no gráfico acima: em 2011 e em 2014. O primeiro pico pode ter sido fruto do receio de calote da dívida pública pelos Estados Unidos da América. Em agosto de 2011, o governo da maior economia do mundo ampliou o limite de dívida pública, fato que permitiu a volta da estabilidade econômica.

Já a subida da volatilidade no segundo semestre de 2014 se deveu a um clima de incerteza quanto à eleição para a presidência da república do Brasil. Ao iniciar o ano de 2015 , percebe-se que a volatilidade voltou para a faixa entre $10 \mathrm{e}$ $20 \%$. 


\section{3 Pesquisas sobre ISR no Mundo}

Antes do surgimento de instrumentos de aferição de ISR no Brasil, alguns países desenvolvidos já tinham desenvolvido meios de avaliá-los. É possível encontrar quantidade expressiva de pesquisas a partir da década de 1990 que abordam o assunto. Dada a relativa maturidade dos mercados europeus e da América do Norte, estes serão abordados nesta revisão.

Em pesquisa realizada acerca do mercado canadense, tomou-se uma amostra de dados relativa ao período 1994 a 2003 para entender se fundos atrelados a ISR teriam uma performance melhor do que fundos tradicionais. A conclusão a que os autores chegaram foi que tais fundos não obtiveram diferenças significativas de retorno em relação aos fundos convencionais (BAUER, DERWALL, OTTEN, 2006).

Por questões de tamanho e expressividade global, o mercado norteamericano é o que apresenta a maior quantidade de estudos relacionados ao tema. Uma das investigações mais citadas é a de Statman (2000). A partir de amostra de dados referentes ao intervalo 1990 a 1998, o autor chegou ao quadro de que o Domini Social Index teve melhor resultado que o S\&P 500 e que fundos de ISR também performaram melhor do que outros convencionais. Entretanto, tais resultados não foram estatisticamente relevantes.

O trabalho de Cheung (2009) debruçou-se sobre uma amostra de dados acerca do Dow Jones Sustainability World Index (DJSI) para saber se o ingresso ou saída de empresas do índice teria capacidade de impactar os níveis de rentabilidade. O estudo de eventos realizado para o período entre os anos de 2002 e 2008 não encontrou evidências fortes de tal hipótese.

A partir de uma quantidade de dados de 16 anos (1987 - 2003), buscouse saber se a atuação de fundos atrelados a comportamentos éticos seria diferente de outros convencionais. A conclusão a que se chegou foi que ambos os tipos de fundos tiveram resultados semelhantes (DERWALL, KOEDIJK, 2008).

De maneira semelhante, Mallett e Michelson (2005) não identificaram haver diferenças de resultado entre os fundos atrelados a ISR e o índice S\&P 500. 
Para chegar a tal fechamento, adotaram-se métodos paramétricos e nãoparamétricos.

Quanto aos mercados europeus, são identificados trabalhos que levam a resultados opostos. De acordo com Platinga e Scholtens (2001), os fundos que adotam investimentos socialmente responsáveis tendem a apresentar resultados melhores do que os demais. Os indicadores de Jensen, Treynor e Sharpe relativos a fundos de ISR do mercado britânico performaram melhor do que os demais (MALLIN et al., 1995).

Já os autores Sánchez e Sotorrío (2005) defenderam que a adoção de critérios sociais nas decisões de investimento carrega um custo para o investidor em termos de menor retorno. Os dados analisados foram do período entre 2003 e 2007.

Por fim, Schroder (2005) debruçou-se sobre 29 índices de ISR de diferentes mercados do mundo. Segundo o autor, tais instrumentos não apresentaram retornos ajustados ao risco diferentes de outros índices adotados como referência.

\section{4 \\ Pesquisas sobre ISR no Brasil}

O mercado acionário brasileiro apresenta, hoje, dois grandes índices que medem ações socialmente responsáveis de empresas: o Índice de Sustentabilidade Empresarial (ISE) e o Índice de Carbono Eficiente (ICO2). É relevante destacar que o primeiro índice que surgiu foi o ISE em 2005, fato que contribui para o maior número de pesquisas disponíveis em relação ao ICO2, lançado em 2010.

Em linhas gerais, os resultados de alguns estudos apontam uma dificuldade em verificar melhorias de rentabilidade em empresas que adotam medidas socioambientalmente corretas. De acordo com Campos e Lemme (2009), há a possibilidade do aumento da rentabilidade ser mitigado devido ao aumento de custos associados às práticas socioambientais.

Seguindo esta hipótese de ISR acarretarem em aumento de gastos, a pesquisa de Oro, Renner e Braun (2013) procurou relacionar a receita líquida de 
empresas listadas no ISE e seus respectivos indicadores socioambientais listados no balanço social. Este estudo verificou uma relação positiva entre a receita líquida de empresas listadas no índice e bons indicadores sociais.

Em trabalho de Machado, Machado e Corrar (2009), investigou-se se o ISE teria um retorno médio maior que os demais índices da Bovespa. Os autores terminam por concluir que o retorno médio dos índices é semelhante. Esses resultados sugerem uma não valorização por parte do mercado dos investimentos socialmente responsáveis.

Segundo Carvalhal e Tavares (2013), não há evidências estatisticamente significantes de que o ingresso no ISE está relacionado a retornos anormais positivos. Já a saída foi vinculada a retornos anormais negativos com relevância estatística.

Ademais, buscou-se entender se empresas listadas no ISE apresentam particularidades quanto ao nível de endividamento e risco. Os autores Teixeira, Nossa e Funchal (2011) concluíram que o fato das empresas listadas terem seu risco reduzido possibilitaria que elas captassem capital de terceiros com maior facilidade. Assim, poderia haver redução do custo de capital e aumento dos níveis de rentabilidade.

Em paralelo, identificaram-se estudos que verificaram a importância do ISE a partir de índices de desempenho financeiro. De acordo com Melo et al. (2012), não há indícios estatisticamente significantes de que o índice de Sharpe de empresas listadas no ISE seja diferente daquelas listadas no IBrX-50.

A partir de análises de Treynor, Jensen e Modigliani e Miller, o ISE também não apresentou particularidades em termo de risco e retorno. Em contrapartida, este índice apresentou risco diversificável baixo e liquidez crescente (CUNHA E SAMANEZ, 2014).

Sob uma ótica positiva, a pesquisa de Machado et al. (2012) provou que as empresas listadas no ISE representam comprometimento real com a responsabilidade social e a sustentabilidade. Já em um estudo de eventos realizado para analisar o efeito da inclusão de empresas neste índice, foram encontradas evidências de retornos anormais positivos (LIMA, 2011). 
Assim, uma hipótese levantada é se o tema vem ganhando importância ao longo do tempo, de modo que os investidores valorizam mais empresas que adotam comportamentos socioambientais corretos.

Quanto ao ICO2, foi identificado um estudo que buscou captar melhorias nos retornos das ações de empresas que ingressaram no índice, ou seja, que compuseram sua primeira carteira. A pesquisa de Barbosa et al. (2013) não rejeitou a hipótese nula de que o anúncio da participação do índice não levou a impactos nos retornos das ações das empresas em questão. Assim, os autores sugerem que o anúncio da participação no ICO2 não influenciou no retorno das ações das empresas.

Já em relação ao custo de capital, Cazzari e Lima (2012) buscaram entender se os acionistas valorizam empresas ambientalmente responsáveis. A partir de um modelo modificado do CAPM, os autores não conseguiram inferir que a participação no ICO2 leva a um menor custo de capital próprio. Ademais, também não foi possível concluir que os acionistas, necessariamente, valorizam empresas ambientalmente responsáveis.

Por fim, o trabalho de Viviani et al. (2014) analisa se é possível correlacionar a presença no ICO2 com indicadores de desempenho empresarial (margem líquida, giro do ativo, taxa de retorno sobre o investimento, entre outros). A conclusão dos autores foi a não observância de correlação estaticamente significante entre a participação no ICO2 e indicadores de desempenho empresarial.

O presente trabalho busca responder a uma sugestão de pesquisa futura apontada por Barbosa et al. (2013): o fato de uma empresa ingressar ou deixar o ICO2 é relevante para o seu nível de rentabilidade? Além disso, procura-se verificar se, ao contrário de pesquisas nacionais e internacionais anteriores a esta, é possível detectar relação positiva entre desempenho financeiro e socioambiental.

A partir de uma amostra de dados atualizada - 2012 a 2015 - buscou-se contribuir para o conhecimento sobre a valorização atribuída por investidores a investimentos socialmente responsáveis. Em seguida, foram comparados os resultados com as pesquisas já realizadas quanto ao tema. 


\section{5 \\ Retorno Anormal}

O método do estudo de eventos se propõe a analisar a relevância estatística de retornos anormais. Sendo assim, é importante definir qual será a forma de calcular o retorno teórico de uma ação e compará-lo com o seu retorno real. De acordo com MacKinley (1997), exitem modelos econômicos e modelos estatísticos.

\subsection{1 \\ Modelos Estatísticos}

Em trabalho de Brown e Warner (1985), analisou-se a influência do uso de retornos diários de ações na metodologia do estudo de eventos. Neste estudo, são encontradas formas estatísticas de se calcular o excesso de retorno de uma ação. São elas:

a) Retornos ajustados à média: nesta equação, o pesquisador compara o retorno real verificado em determinado dia com a média aritmética dos retornos diários ao longo de determinado período.

$$
A_{i, t}=R_{i, t}-\bar{R}_{i}(2)
$$

Em que:

- $A_{i, t}$ é o excesso de retorno diário da ação "i" no dia " t";

- $R_{i, t}$ é o retorno diário real verificado da ação "i" no dia " $\mathrm{t}$ ";

- $\bar{R}_{i}$ é a média aritmética dos retornos diários da ação "i"

b) Retornos ajustados ao mercado: similiar à equação anterior, esta fórmula compara o retorno diário real com o retorno diário do mercado, geralmente pautado em um índice amplamente aceito.

$$
A_{i, t}=R_{i, t}-R_{m, t}(3)
$$

Em que:

- $R_{m, t}$ é o retorno do mercado no dia " $\mathrm{t}$ " 
c) Retornos ajustados ao mercado e ao risco: trata-se de uma forma de cálculo baseada na técnica de mínimos quadrados (OLS), que é utilizada para estimar os parâmetros de um modelo de regressão linear. De acordo com Soares et al. (2002), este modelo é mais eficaz do que os apresentados anteriormente. Logo, foi adotado nesta pesquisa.

$$
A_{i, t}=R_{i, t}-\left(\propto_{i, t}+\beta_{i} R_{M, t}\right)(4)
$$

Em que:

- $\left(\propto_{i t}+\beta_{i} r_{M, t}\right)$ é o retorno esperado da ação "i”" para o dia " $\mathrm{t}$ "

\subsection{2}

\section{Modelos Econômicos}

Uma das principais diferenças entre os modelos estatísticos e os modelos econômicos está na existência de hipóteses restritivas que suportam a base teórica desses. Os modelos econômicos brevemente apresentados aqui são o Capital Asset Pricing Model (CAPM) e o Arbitrage Price Theory (APT).

O CAPM foi apresentado na década de 1960 por Sharpe (1964) e Lintner (1965) com o objetivo de determinar qual seria o retorno de um ativo de acordo com a sua sensibilidade a movimentos da carteira de mercado. Seus autores adotaram hipóteses restritivas, tais como: não existência de custos de transação, simetria de informações no mercado, entre outras (PÓVOA, 2012).

O retorno anormal medido pelo CAPM é:

$$
A_{i}=R_{i, t}-\left(R_{f}+\beta_{i} x\left(R_{m}-R_{f}\right)\right)(5)
$$

Em que:

- $R_{f}$ é a taxa livre de risco;

- $\quad \beta_{i}$ é o beta da ação “i”;

- $\left(R_{m}-R_{f}\right)$ é o prêmio de risco

Em suma, o CAPM propôs que o retorno de uma ação é uma relação linear entre o prêmio de risco do mercado e o risco sistemático da ação. Sua base teórica está vinculada aos estudos de Markowitz sobre diversificação de carteiras. Embora seja uma relação simples, seu uso é expressivo em trabalhos científicos. 
Já o modelo APT baseia-se no pressuposto de que o retorno esperado de uma ação é resultante de um relação linear de "k" fatores e da não-existência de arbitragem. Em outras palavras, a noção do CAPM de que o retorno de uma ação depende da sensibilidade a apenas um fator - o beta - é extendida para outros. Assim, o retorno pode ser afetado por diversos fatores macroeconômicos, que não são especificados pelo modelo original de Ross do ano de 1976.

$$
A_{i, t}=R_{i, t}-\left(E\left(R_{i, t}\right)+\beta_{i, 1} F_{1}+\cdots \beta_{i, k} F_{k}\right)(6)
$$

O termo $\beta_{\mathrm{i}, \mathrm{k}} \mathrm{F}_{\mathrm{k}}$ representa o beta da ação "i" ao fator " $\mathrm{k}$ " multiplicado pelo fator " $k$ ". 


\section{3 \\ Metodologia}

A presente pesquisa tentou identificar mudanças significativas nos níveis de rentabilidade de empresas que ingressaram ou saíram do ICO2. Para atingir este objetivo, a metodologia aplicada foi a de estudo de eventos, que será apresentada no decorrer deste capítulo.

Um estudo de eventos procura determinar se um evento ou um anúncio causou movimentos anormais na cotação da ação de determinada empresa. Os retornos anormais são calculados pela diferença entre o retorno atual da ação e seu retorno esperado (BENNINGA, 2008).

De modo a facilitar a compreensão e a aplicação da metodologia, seguem abaixo os procedimentos ou etapas básicos que foram utilizados neste estudo de eventos. São eles: 


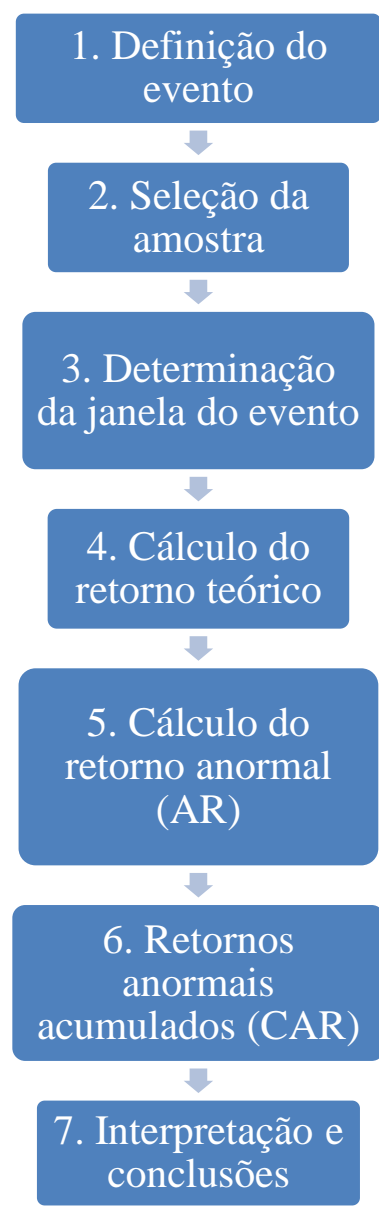

Figura 2: Etapas do estudo de eventos

Fonte: adapatada de MacKinlay (1997)

\section{1 Definição do Evento e Seleção da Amostra}

Primeiramente, houve a definição do evento que será estudado pela pesquisa. Trata-se do ingresso ou saída de determinada empresa do ICO2, seja por vontade própria ou por não cumprimento dos requisitos definidos pela metodologia do índice.

Em seguida, determinou-se o conjunto de empresas que serão analisadas e que comporão a amostra. Foram selecionadas aquelas que participaram do ICO2 no período de março de 2012 a janeiro de 2015. Notou-se que a carteira do índice é atualizada a cada trimestre, logo foi preciso analisar cada composição no intervalo de tempo entre 2012 e 2015. Tais mudanças na constituição do ICO2 foram verificadas na base de dados Economática. 
Dado que esta pesquisa visa estudar as empresas que entraram ou saíram do índice ao longo do período, as ações que se mantiveram no índice ao longo do tempo foram excluídas. Assim, restaram 21 empresas. Deste total, foram retiradas 5 empresas que entraram e saíram do índice ao longo período.

Ademais, as empresas Redecard e Tele Norte Leste não foram negociadas em outubro e abril de 2012, respectivamente. Com o objetivo de não comprometer os resultados, tais empresas foram excluídas da amostra.

Em razão da pouca quantidade de dados, as ações da Cosan Logística e Klabin foram eliminadas. A primeira porque começou a ser cotada em outubro de 2014 e a segunda em virtude de suas cotações terem se iniciado apenas três meses antes de ingressar no índice.

Enfim, a amostra final ficou com 12 empresas, sendo quatro ingressantes e oito excluídas. São elas:

\begin{tabular}{|c|c|c|}
\hline Empresa & Código Bolsa & $\begin{array}{c}\text { Data de } \\
\text { Ingresso }\end{array}$ \\
\hline Banco Bradesco SA & BBDC3 & out/13 \\
\hline Embraer SA & EMBR3 & jul/13 \\
\hline Oi SA & OIBR4 & jul/12 \\
\hline $\begin{array}{c}\text { Ultrapar } \\
\text { Participações SA }\end{array}$ & UGPA3 & $\mathrm{jul} / 13$ \\
\hline
\end{tabular}

Tabela 3: Empresas Incluídas no ICO2

Fonte: elaborada pelo autor 


\begin{tabular}{|c|c|c|}
\hline Empresa & Código Bolsa & $\begin{array}{c}\text { Último mês } \\
\text { no índice }\end{array}$ \\
\hline $\begin{array}{c}\text { All América Latina } \\
\text { Logística SA }\end{array}$ & ALLL3 & mar/14 \\
\hline Braskem SA & BRKM5 & set/14 \\
\hline $\begin{array}{c}\text { Centrais Elétricas } \\
\text { Brasileiras SA }\end{array}$ & ELET3 & jun/12 \\
\hline Eletropaulo & ELPL4 & jun/13 \\
\hline $\begin{array}{c}\text { Gol Linhas Aéreas } \\
\text { Inteligentes SA }\end{array}$ & GOLL4 & set/13 \\
\hline $\begin{array}{c}\text { MMX Mineração e } \\
\text { Metálicos SA }\end{array}$ & MMXM3 & $\mathrm{mar} / 14$ \\
\hline $\begin{array}{c}\text { OGX Petróleo e Gas } \\
\text { Participações SA }\end{array}$ & OGXP3 & dez/13 \\
\hline PDG Realty & PDGR3 & mar/14 \\
\hline
\end{tabular}

Tabela 4: Empresas Excluídas do ICO2

Fonte: elaborada pelo autor

\section{2}

\section{Linha do Tempo do Evento}

A fim de facilitar a análise dos dados coletados da amostra, é comum que os valores de uma série sejam divididos em janelas que têm diferentes propósitos. Apesar de não haver um formato único na construção da linha do tempo de um estudo de eventos, foram adotados três tipos de janelas. São elas:

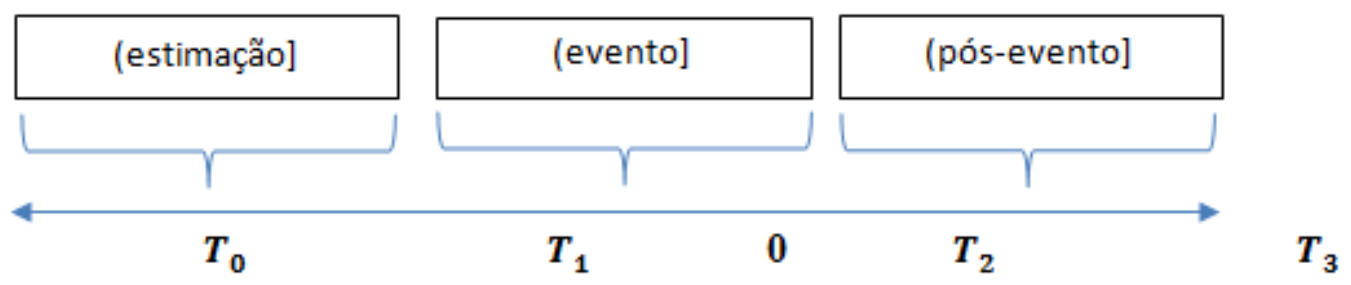

Figura 3: Linha do tempo do estudo de eventos

Fonte: adaptada de McKinlay (1997) e Benninga (2008)

A janela de estimação procurou revelar qual seria o comportamento padrão ou normal da ação. Assim, seus valores serviram para estabelecer os parâmetros utilizados no modelo de regressão linear. Ademais, influenciaram o retorno previsto das ações e seus retornos anormais. 
Já a janela de eventos procura revelar se o anúncio do evento foi antecipado ou postecipado pelo mercado. Em outras palavras, buscou-se entender se o evento gerou impactos relevantes antes, durante ou após o acontecimento objeto de análise do estudo.

Por último, a janela pós-evento costuma entender o desempenho de longo prazo da ação após o evento. Na prática, foram identificados poucos estudos que se debruçaram especificamente nessa janela. Dada a escassez de cotações, esta pesquisa não se debruçou sobre os dados especificamente deste período de tempo.

Neste trabalho, a janela de estimação corresponde a, aproximadamente, um ano antes do evento. Em termos de dias, são 250 dias úteis em média. Já a janela do evento contou com um total de 11 dias, especificamente entre os dias -5 (cinco dias antes do evento) e +5 (cinco dias após o evento).

Para compor a janela de estimação, utilizou-se a base de dados Bloomberg em que foram coletados as séries relativas às cotações das ações e do desempenho do índice Ibovespa.

\section{3 Retornos Teórico, Anormal e Acumulado}

Definida a linha do tempo do evento, o próximo passo foi calcular o retorno teórico ou esperado da ação para cada dia da série. Adotou-se o modelo ajustado ao mercado e ao risco, que é uma regressão linear simples a partir dos valores de fechamento verificados ao longo da janela de estimação. Sua fórmula é:

$$
R_{i t}=\propto_{i}+\beta_{i} R_{M t}(7)
$$

Em que:

- $R_{i t}$ é o retorno esperado da ação.

- $\propto_{i}$ é o coeficiente linear da reta de regressão.

- $\quad \beta_{i}$ é o beta da ação, ou a covariância entre os retornos da ação e do mercado.

- $R_{M t}$ é o retorno de mercado, representado pelo índice Ibovespa 
De posse dos retornos esperados da ação para cada dia, compararam-se tais valores com o retorno efetivamente alcançado. Achou-se, assim, o retorno anormal da ação, de acordo com o retorno ajustado ao mercado e ao risco elucidado no capítulo dois:

$$
A_{i t}=R_{i t}-\left(\propto_{i t}+\beta_{i} R_{M t}\right)(4)
$$

Com o objetivo de trabalhar com dados cuja distribuição de frequências seja aproximadamente simétrica, foi feita uma adaptação a partir do uso de capitalização contínua. Desta forma, a transformação dos dados foi:

$$
R_{i t}=\operatorname{Ln} \frac{P_{t}}{P_{t-1}}
$$

Em que:

- $R_{i t}$ é o retorno logaritimizado da ação "i" na data " $\mathrm{t}$ "

- $P_{t}$ é o preço da ação na data " $\mathrm{t}$ "

- $P_{t-1}$ é o preço da ação na data "t-1"

De posse dos retornos anormais, calcularam-se os retornos anormais acumulados (CAR) da janela de evento:

$$
C A R_{t}=\sum_{j=1}^{t} A R_{T_{1}+j}(9)
$$

Em que:

- $C A R_{t}$ são os retornos anormais acumulados;

- $\sum_{j=1}^{t} A R_{T_{1}+j}$ é a soma dos retornos anormais

\section{4}

\section{Teste de Hipótese}

Neste trabalho foram realizados dois testes de hipóteses para entender a relevância de resultados achados. Desta maneira, calcularam-se testes t que identificaram a significância estatística dos valores dos retornos anormais (AR) e dos retornos anormais acumulados (CAR). 
A hipótese nula é a de que o retorno anormal é igual a zero, ao passo que a hipótese alternativa é a de que seu valor é diferente de zero. A significância dos retornos anormais foi verificada a partir da seguinte equação:

$$
t_{A R_{i, t}}=\frac{A R_{i, t}}{S_{A R_{t}}}(10)
$$

Em que:

- $t_{A R_{i, t}}$ é o valor do teste $\mathrm{t}$

- $A R_{i, t}$ é o retorno anormal da ação "i" no tempo " $\mathrm{t}$ "

- $S_{A R_{t}}$ é o erro padrão da equação 7

Já os retornos anormais foram testados pela seguinte relação:

$$
t_{A R_{i, t}}=\frac{C A R_{i, t}}{S_{C A R_{t}}}
$$

Em que:

- $C A R_{i, t}$ é o retorno anormal acumulado da ação "i" no período " $\mathrm{t}$ "

- $S_{C A R_{t}}$ é o erro padrão do retorno anormal acumulado

A fórmula que descreve o $S_{C A R_{t}}$ é:

$$
S_{C A R_{t}}=\sqrt{L x S_{A R_{t}}^{2}}(12)
$$

Em que:

- $L$ é a quantidade de retornos anormais somados 


\section{Resultados}

Este capítulo apresenta os resultados desta pesquisa a partir de duas maneiras: estatística descritiva e estudo de eventos. Sendo assim, buscou-se entender melhor o ainda pouco explorado ICO2 e avançar nos estudos sobre investimentos socialmente responsáveis no Brasil.

\section{1 \\ Estatística Descritiva}

Antes de partir para o estudo de eventos propriamente, a estatística descritiva procurou ter um primeiro contato com a amostra da pesquisa. Desta forma, foram observadas as medidas de média, desvio padrão, coeficiente de variação, curtose, assimetria e teste de Jarque Bera (JB) das empresas verificadas.

Os resultados obtidos foram:

\begin{tabular}{|l|c|c|r|r|r|l|}
\hline Ação & \multicolumn{1}{|c|}{ Média } & $\begin{array}{l}\text { Desvio } \\
\text { Padrão }\end{array}$ & $\begin{array}{l}\text { Coeficiente } \\
\text { Variação }\end{array}$ & \multicolumn{1}{l|}{ Curtose } & \multicolumn{1}{l|}{ Assimetria } & \multicolumn{1}{l|}{ JB } \\
\hline ALLL3 & $-0,001398$ & 0,025716 & $-18,394850$ & 12,752074 & 1,560033 & 0,000000 \\
\hline BBDC3 & 0,001578 & 0,018827 & 11,930925 & 3,272563 & 0,153526 & 0,394200 \\
\hline BRKM5 & $-0,000380$ & 0,016690 & $-43,921053$ & 4,736287 & $-0,622856$ & 0,829200 \\
\hline ELET3 & $-0,001701$ & 0,022061 & $-12,969430$ & 6,759265 & $-0,307433$ & 0,000000 \\
\hline ELPL4 & $-0,005597$ & 0,026047 & $-4,653743$ & 4,688271 & 0,344549 & 0,000000 \\
\hline EMBR3 & 0,001794 & 0,020855 & 11,624861 & 4,755272 & 0,113201 & 0,000000 \\
\hline GOLL4 & 0,000491 & 0,035711 & 72,731161 & 4,404667 & 0,650605 & 0,000000 \\
\hline MMXM3 & $-0,006859$ & 0,066861 & $-9,747922$ & 6,800646 & 0,752069 & 0,000000 \\
\hline OGXP3 & $-0,012702$ & 0,099736 & $-7,851992$ & 7,148023 & $-0,383376$ & 0,000000 \\
\hline OIBR4 & $-0,002566$ & 0,029515 & $-11,502338$ & 26,265963 & $-2,961109$ & 0,000000 \\
\hline PDGR3 & $-0,003437$ & 0,032414 & $-9,430899$ & 3,248463 & 0,190252 & 0,321600 \\
\hline UGPA3 & 0,000445 & 0,014181 & 31,867416 & 6,154005 & $-0,039142$ & 0,000000 \\
\hline
\end{tabular}

Tabela 5: Estatística Descritiva

Fonte: elaborada pelo autor

Os valores relativos ao retorno diário médio evidenciaram o baixo desempenho das empresas do ICO2, em que quase $70 \%$ da amostra apresentou 
valores diários negativos. O valor médio diário máximo foi de 0,1794\%, relacionado à Embraer.

O coeficiente de variação $(\mathrm{CV})$, medida de dispersão relativa dos dados, teve uma variedade de valores. A Eletropaulo apresentou o menor CV em módulo e a Gol Linhas Aéreas Inteligentes teve o maior CV. Existe a chance de tal diferença de resultados ser relacionada aos setores em que as empresas atuam.

Todas as ações obtiverem curtose superior a três, fato que indica que suas funções de probabilidade são leptocúrticas. Logo, há chances superiores a distribuição normal de se obterem valores distantes da média. Quanto à assimetria, a maior parte da amostra apresentou valores positivos.

Por fim, o teste de Jarque-Bera (JB) testou a hipótese nula de normalidade da série de dados. As ações do Banco Bradesco, da Braskem e da PDG demonstraram distribuição normal, ao passo que as demais tiveram tal hipótese fortemente rejeitada devido ao seu baixo p-valor.

\section{2 \\ Estudo de Eventos}

A próxima forma de análise foi sob a ótica dos retornos anormais verificados no período entre os cinco dias anteriores ao evento e os cinco dias após. Além de analisar cada dia independentemente, foi estudado também o retorno acumulado de cada uma das empresas.

Os símbolos $* * *, * * \mathrm{e} *$ das tabelas a seguir indicam a significância estatística a $1 \%, 5 \%$ e $10 \%$, respectivamente. Primeiramente, são apresentados os resultados para as ações cujo evento é o ingresso no ICO2: 


\begin{tabular}{|c|c|c|c|c|}
\hline Tempo & OIBR 4 & EMBR3 & UGPA3 & $\overline{\text { BBDC3 }}$ \\
\hline$A R_{-5}$ & $1,84 \%$ & $-1,49 \%$ & $-1,68 \%$ & $-0,03 \%$ \\
\hline$A R_{-4}$ & $5,33 \% * *$ & $-2,78 \%$ & $-0,01 \%$ & $-0,65 \%$ \\
\hline$A R_{-3}$ & $-0,32 \%$ & $0,94 \%$ & $2,52 \% *$ & $0,49 \%$ \\
\hline$A R_{-2}$ & $0,14 \%$ & $1,09 \%$ & $3,96 \% * * *$ & $1,85 \%$ \\
\hline$A R_{-1}$ & $-1,31 \%$ & $0,74 \%$ & $0,27 \%$ & $-2,21 \%$ \\
\hline$A R_{0}$ & $2,74 \%$ & $1,69 \%$ & $0,47 \%$ & $0,07 \%$ \\
\hline$A R_{+1}$ & $4,57 \% *$ & $0,82 \%$ & $-1,01 \%$ & $0,67 \%$ \\
\hline$A R_{+2}$ & $4,27 \%$ & $0 \%$ & $0,04 \%$ & $0,67 \%$ \\
\hline$A R_{+3}$ & $0,56 \%$ & $-2,81 \%$ & $-0,56 \%$ & $-0,59 \%$ \\
\hline$A R_{+4}$ & $2,07 \%$ & $2,24 \%$ & $-0,58 \%$ & $0,61 \%$ \\
\hline$A R_{+5}$ & $3,17 \%$ & $0,04 \%$ & $0,20 \%$ & $-0,60 \%$ \\
\hline $\begin{array}{l}C A R[-1,+1] \\
\text { Estatística t }\end{array}$ & $\begin{array}{l}4,17 \% \\
0,90\end{array}$ & $\begin{array}{l}3,24 \% \\
0,95\end{array}$ & $\begin{array}{l}-0,26 \% \\
-0,11\end{array}$ & $\begin{array}{l}-1,47 \% \\
-0,91\end{array}$ \\
\hline $\begin{array}{l}\text { CAR }[-5,+1] \\
\text { Estatística t }\end{array}$ & $\begin{array}{l}12,97 \% * \\
1,84\end{array}$ & $\begin{array}{l}1,00 \% \\
0,19\end{array}$ & $\begin{array}{l}4,53 \% \\
0,98\end{array}$ & $\begin{array}{l}0,19 \% \\
0,04\end{array}$ \\
\hline $\begin{array}{l}C A R[-5,+5] \\
\text { Estatística } \mathrm{t}\end{array}$ & $\begin{array}{l}23,04 \% * * * \\
2,6\end{array}$ & $\begin{array}{l}0,48 \% \\
0,07\end{array}$ & $\begin{array}{l}3,62 \% \\
0,78\end{array}$ & $\begin{array}{l}0,28 \% \\
0,05\end{array}$ \\
\hline
\end{tabular}

Tabela 6: Empresas Ingressantes no ICO2

Fonte: elaborada pelo autor

A partir da tabela seis, observou-se que a ação OIBR4 foi a que apresentou maior quantidade de retornos anormais significativamente relevantes. Seu retorno anormal acumulado entre os dias -5 e +5 foi superior a $20 \%$ e significante a $1 \%$. Além disso, houve retornos anormais positivos e significantes nos dias $-4,+1$ e no acumulado entre -5 e +1 .

Além da OIBR4, apenas a UGPA3 apresentou retornos anormais significantes, especificamente nos dias -3 e -2 . Não foram verificados retornos anormais relevantes nas demais empresas, o que sugere que o ingresso no ICO2 não afetou seus níveis de rentabilidade.

Já quanto às empresas que deixaram o ICO2, os resultados verificados foram os seguintes: 


\begin{tabular}{|l|l|l|l|l|}
\hline Tempo & ALL3 & ELET3 & ELPL4 & GOLL4 \\
\hline$A R_{-5}$ & $-1,03 \%$ & $1,14 \%$ & $2,10 \%$ & $-1,49 \%$ \\
\hline$A R_{-4}$ & $-0,14 \%$ & $0,25 \%$ & $2,18 \%$ & $-0,69 \%$ \\
\hline$A R_{-3}$ & $0,62 \%$ & $2,80 \%$ & $-4,18 \% *$ & $-0,35 \%$ \\
\hline$A R_{-2}$ & $-0,36 \%$ & $1,68 \%$ & $-1,68 \%$ & $-0,30 \%$ \\
\hline$A R_{-1}$ & $3,18 \%$ & $-0,51 \%$ & $-2,03 \%$ & $3,05 \%$ \\
\hline$A R_{0}$ & $3,42 \%$ & $-0,11 \%$ & $-0,19 \%$ & $-1,55 \%$ \\
\hline$A R_{+1}$ & $0,05 \%$ & $1,12 \%$ & $-2,88 \%$ & $1,87 \%$ \\
\hline$A R_{+2}$ & $-1,65 \%$ & $0,42 \%$ & $-1,40 \%$ & $-0,77 \%$ \\
\hline$A R_{+3}$ & $-0,21 \%$ & $-0,68 \%$ & $1,40 \%$ & $-0,81 \%$ \\
\hline$A R_{+4}$ & $-2,09 \%$ & $-2,31$ & $5,95 \% * * *$ & $-1,11 \%$ \\
\hline$A R_{+5}$ & $-1,80 \%$ & $-0,07 \%$ & $5,44 \% * *$ & $-1,43 \%$ \\
\hline$C A R[-1,+1]$ & $6,66 \%$ & $0,5 \%$ & $-5,10 \%$ & $3,37 \%$ \\
\hline Estatística t & 1,62 & 0,15 & $-1,25$ & 0,61 \\
\hline$C A R[-5,+1]$ & $\begin{array}{l}5,74 \% \\
\text { Estatística t }\end{array}$ & 0,91 & $\begin{array}{l}6,34 \% \\
1,24\end{array}$ & $\begin{array}{l}-6,38 \% \\
-1,02\end{array}$ \\
\hline $\begin{array}{c}\text { CAR }[-5,+5] \\
\text { Estatística t }\end{array}$ & $-0,01 \%$ & $\begin{array}{l}3,74 \% \\
0,58\end{array}$ & $\begin{array}{l}4,70 \% \\
0,60\end{array}$ & $0,06 \%$ \\
\hline
\end{tabular}

Tabela 7: Empresas Excluídas no ICO2 (1)

Fonte: elaborada pelo autor 


\begin{tabular}{|c|c|c|c|c|}
\hline Tempo & MMXM3 & OGXP3 & \begin{tabular}{|l|} 
PDGR3 \\
\end{tabular} & BRKM5 \\
\hline$A R_{-5}$ & $3,68 \%$ & $9,02 \%$ & $-0,31 \%$ & $3,78 \%$ \\
\hline$A R_{-4}$ & $-2,87 \%$ & $-10,17 \%$ & $-3,69 \%$ & $0,73 \%$ \\
\hline$A R_{-3}$ & $0,95 \%$ & $16,63 \% *$ & $0,64 \%$ & $3,32 \%$ \\
\hline$A R_{-2}$ & $-5,78 \%$ & $5,15 \%$ & $3,54 \%$ & $0,51 \%$ \\
\hline$A R_{-1}$ & $-0,26 \%$ & $3,61 \%$ & $1,22 \%$ & $-1,52 \%$ \\
\hline$A R_{0}$ & $11,54 \% *$ & $4,96 \%$ & $-0,04 \%$ & $-1,90 \%$ \\
\hline$A R_{+1}$ & $-2,37 \%$ & $0,76 \%$ & $0,34 \%$ & $-0,99 \%$ \\
\hline$A R_{+2}$ & $4,13 \%$ & $16,49 \% *$ & $-1,66 \%$ & $-0,25 \%$ \\
\hline$A R_{+3}$ & $4,22 \%$ & $-6,47 \%$ & $3,21 \%$ & $-1,84 \%$ \\
\hline$A R_{+4}$ & $-4,91 \%$ & $-0,01 \%$ & $-0,06 \%$ & $0,74 \%$ \\
\hline$A R_{+5}$ & $1,73 \%$ & $13,94 \%$ & $9,30 \% * * *$ & $-1,96$ \\
\hline $\begin{array}{l}\text { CAR }[-1,+1] \\
\text { Estatística } \mathrm{t}\end{array}$ & $\begin{array}{l}8,91 \% \\
0,85\end{array}$ & $\begin{array}{l}9,33 \% \\
0,61\end{array}$ & $\begin{array}{l}1,52 \% \\
0,34\end{array}$ & \begin{tabular}{|l}
$-4,42 \% *$ \\
$-1,78$
\end{tabular} \\
\hline $\begin{array}{l}C A R[-5,+1] \\
\text { Estatística } \mathrm{t}\end{array}$ & $\begin{array}{l}4,89 \% \\
0,31\end{array}$ & $\begin{array}{l}29,96 \% \\
1,28\end{array}$ & $\begin{array}{l}1,70 \% \\
0,25\end{array}$ & \begin{tabular}{|l|}
$3,92 \%$ \\
1,03
\end{tabular} \\
\hline $\begin{array}{l}\text { CAR }[-5,+5] \\
\text { Estatística } \mathrm{t}\end{array}$ & $\begin{array}{l}10,06 \% \\
0,50\end{array}$ & $\begin{array}{l}53,91 \% * \\
1,84\end{array}$ & $\begin{array}{l}12,49 \% \\
1,44\end{array}$ & $\begin{array}{l}0,61 \% \\
0,13\end{array}$ \\
\hline
\end{tabular}

Tabela 8: Empresas Excluídas no ICO2 (2)

Fonte: elaborada pelo autor

A tabela 7 revelou que apenas a ELPL4 teve retornos anormais significantes, especificamente nos dias $-3,+4$ e +5 , sendo o primeiro negativo e os demais positivos. A ALL3, ELET3 e GOLL4 obtiveram valores próximos a 0 e sem relevância estatística.

Por último, a tabela 8 mostrou que três quartos das empresas tiveram retornos anormais positivos e significantes, sendo que a OGXP3 apresentou retornos anormais acumulados entre os dias -5 e +5 superior a $50 \%$. Por outro lado, a BRKM5 teve resultado negativo com a saída do ICO2.

Enfim, observou-se que no grupo das empresas que ingressaram todos os retornos anormais significativos foram positivos. Já entre as que saíram, houve duas empresas com retorno anormal negativo significante. Assim, levanta-se a suspeita de quedas na rentabilidade serem resultantes da saída do ICO2. 


\section{5 \\ Conclusão}

Este trabalho procurou contribuir para o conhecimento acerca de investimentos socialmente responsáveis no Brasil. Especificamente, debruçou-se sobre o Índice de Carbono Eficiente (ICO2), ferramenta recém-criada pela BM\&FBovespa que busca reunir empresas consideradas carbono eficientes.

Foi detectado que mais da metade da amostra obteve retornos diários médios negativos, o que caracteriza um fraco resultado. Ressalta-se que tal desempenho pode ser melhorado no futuro em virtude do crescimento da economia brasileira e do mercado de ações em geral.

No estudo de eventos foram criados os grupos das empresas que ingressaram e das que saíram do índice. Em termos de significância, identificaram-se casos de empresas que, ao deixarem o índice, tiveram retornos negativos e, por outro lado, ações ingressantes que tiveram aumento na rentabilidade.

Os impactos verificados nos retornos das empresas que entraram e saíram do ICO2 corroboram, conjuntamente, a ideia de que os investidores valorizam empresas carbono eficientes. Em outras palavras, ficou revelado que os investimentos socialmente responsáveis podem resultar em um ganho para as empresas em termos de valor de mercado.

Ademais, pode-se inferir que a metodologia adotada pela BM\&FBovespa para a atração de empresas para o ICO2 é relevante para o mercado. Caso contrário, os investidores não mudariam a forma de precificar uma empresa devido à sua presença no índice. Ou seja, a participação no ICO2 é percebida sim como uma evidência de que são adotadas práticas carbono eficientes no modelo de negócios.

Desta forma, esta pesquisa representou um avanço no entendimento acerca do ICO2 uma vez que, ao contrário dos resultados de Barbosa et al. (2013), foi possível detectar retornos anormais positivos e significantes em empresas 
ingressantes no índice. Ademais, houve aquelas que deixaram a carteira e obtiveram retornos anormais negativos e significantes.

Em suma, procurou-se suprir uma lacuna existente nas pesquisas sobre investimentos socialmente responsáveis no Brasil. Buscou-se entender, sob a ótica do ICO2, se os investidores brasileiros valorizam uma organização que se compromete em ser carbono eficiente. Até então, tal estudo havia sido feito apenas no momento do surgimento da carteira.

Visto que o índice é recente e existem ainda poucos dados históricos, existe a possibilidade de que resultados com perfil mais significante venham a ocorrer em um período de tempo maior do que o verificado. Assim, o comportamento das ações seria afetado pela presença ou não no índice no médio ou longo prazo.

Como principal sugestão de pesquisas futuras, indica-se a necessidade de reunir maior número de dados. Conforme a amostra cresça, é provável que os resultados sejam cada vez mais confiáveis e reveladores. Neste momento, este trabalho buscou ser um primeiro passo para entender a relação que possa existir entre a entrada ou saída de uma empresa do ICO2 e a existência de retornos anormais para os acionistas. 


\section{Referências}

ASHLEY, Patrícia Almeida (org.). Ética e responsabilidade social nos negócios. São Paulo: Saraiva, 2a edição, 2010.

BARBIERI, José Carlos. Gestão ambiental empresarial: conceitos, modelos e instrumentos. São Paulo: Saraiva, 2011.

BARBOSA, J. S.; ALTOÉ, S. M. L.; SILVA, W. V.; ALMEIDA, L. B. Índice carbono eficiente (ICO2) e retorno das ações: um estudo de eventos em empresas não financeiras de capital aberto. Revista de Contabilidade e Organizações, v. 7, n. 19, p. 59-69, 2013.

BAUER, R.; DERWALL, J.; OTTEN, R. The Ethical Mutual Fund Performance Debate: New Evidence from Canada. Journal of Business Ethics, v. 70, p.111124, 2006.

BENNINGA, Simon. Financial Modeling. Massachusetts: MIT Press, $3^{\mathrm{a}}$ edição, 2008

BOLSA BRASILEIRA DE MERCADORIAS, AÇÕES E FUTUROS (BM\&FBOVESPA). Índice de Sustentabilidade Empresarial. Disponível em: $<<$ http://www.isebvmf.com.br/>>. Acesso em 14/07/2015.

BOLSA BRASILEIRA DE MERCADORIAS, AÇÕES E FUTUROS (BM\&FBOVESPA). Índice de Carbono Eficiente. Disponível em: $<<$ http://www.bmfbovespa.com.br/Indices/download/ICO2-Metodologia-ptbr.pdf $>>$. Acesso em 02/09/2015.

BOLSA BRASILEIRA DE MERCADORIAS, AÇÕES E FUTUROS (BM\&FBOVESPA) site. Disponível em: <<http://www.bmfbovespa.com.br〉>. Acesso em 18/07/2015

BRASIL. Constituição da República Federativa do Brasil de 1988.

BROWN, S., WARNER, J. Using Daily Stock Returns. The case of Event Studies. Journal of Financial Economics, v. 4, p.3-31, 1985.

CAMPOS, F. M.; LEMME, C. F., Investimento Socialmente Responsável no Mercado de Capitais: Análise do Desempenho de Índices Internacionais e Fundos de Ações brasileiros que Consideram Questões Ambientais e Sociais, Revista Eletrônica de Administração, v. 15, n. 2, p. 1-21, 2009. 
CARROL, A.B. "The Pyramid of Corporate Social Responsibility: Toward the Moral Management of Organizational Stakeholders", Business Horizons, v. 34, no 4, pp. 39-48, jul./ago. 1991.

CARVAlHAL, A.; TAVARES, E. Does Social Responsability Enhance Firm Value and Return in Brazil?,Corporate Ownership \& Control, v.10, issue 2, p.253-257, 2013.

CAZZARI, R. B.; LIMA, I. S.. A relação entre empresas que participam do ICO2 e o custo de capital próprio. In: Congresso USP de Controladoria e Contabilidade, 12, 2012, São Paulo. Anais. São Paulo, 2012.

CHEUNG, A. Do Stock Investors Value Corporate Sustainability? Evidence from an Event Study. Griffith University Working Paper, 2009.

COHEN, M.; COSTA, L. S. V. Projetos de Desenvolvimento Sustentável para Unidades de Conservação Ambiental Urbanas: Entendimento da Questão e Levantamento da Rede de Stakeholders. XXVIII Encontro Nacional da Associação Nacional de Pós-graduação e Pesquisa em Administração, Curitiba, Brasil. CD-ROM, 2004.

CUNHA, F. A. F. S.; SAMANEZ, C. P. Análise de desempenho dos investimentos sustentáveis no mercado acionário brasileiro. Associação Brasileira de Engenharia de Produção, 24 (2), pp. 420-434, 2014.

DERWALL, J.; KOEDIJK, K. Socially Responsible Fixed-Income Funds. Tilburg University Working Paper, 2008.

DOW JONES SUSTAINABILITY INDEX (DJSI) site. Disponível em: $<<$ http://www.sustainability-indices.com>>. Acesso em 02/08/2015.

FREDERICK, W. C. From CSRI to CSR2: The maturing of business-andsociety thought. Graduate School of Business, University of Pittsburgh, 1978.

FREEMAN, R. Strategic Management: A Stakeholder Approach. Boston: Pitman, 1984.

FRIEDMAN, R. E. "The Social Responsibility of Business is to Increase its Profits", New York Times Magazine, set. 1970.

HULL, John C. Option, Futures \& Other Derivatives. New Jersey: PrenticeHall, 6th edition, 2008.

LIMA, B.Q.A. Efeitos nos Retornos das Ações da Inclusão de Empresas no Índice de Sustentabilidade Empresarial da BM\&F Bovespa. Instituto COPPEAD de Administração, Universidade Federal do Rio de Janeiro, 2011.

LINTNER, J., Security prices, risk and maximal gains from diversification. Journal of Finance, v.20, nº 4, pp.587-615, 1965. 
MACEDO, F., BARBOSA, H., GALLEGARI, I., MONZONI, M., SIMONETTI, R., (2012). O Valor do ISE: principais estudos e a perspectiva dos investidores, São Paulo: BM\&fbovespa.

MACHADO, M. A. V.; MACEDO, M. A. S.; MACHADO, M. R.; SIQUEIRA, J. R. M. Análise da relação entre investimentos socioambientais e a inclusão de empresas no índice de sustentabilidade empresarial (ISE) da BM\&FBOVESPA. Revista de Ciências da Administração, 14 (32), pp. 141$156,2012$.

MACHADO, M. R.; MACHADO, M. A. V.; CORRAR, L. J., Desempenho do Índice de Sustentabilidade Empresarial (ISE) da Bolsa de Valores de São Paulo. Revista Universo Contábil, v. 5, n. 2, p. 24-38, 2009.

MACKINLAY, A. Event Studies in Economic and Finance. Journal of Economic Literature, v. XXXV, p. 13-39, 1997.

MALLETT, J.; MICHELSON, S. Green Investing, Socially Responsible Investing, or Index Funds? Stetson University Working Paper, 2005.

MALLIN, C. A; SAADOUNI, B; BRISTON, R. J. The Financial Performance of Ethical Investment Funds. Journal of Business Finance \& Accouting, v. 22, n.4, pp.483 - 496, 1995.

MELO, R. A.; MANHÃES, J. V. P.; MACEDO, M. A. S. Desempenho do Índice de Sustentabilidade Empresarial (ISE) da Bolsa de Valores de São Paulo sob a ótica do Índice de Sharpe. Revista Economia \& Gestão, v. 12, n.28, pp. 75-104, 2012.

MINISTÉRIO DA CIÊNCIA E TECNOLOGIA site. Disponível em: $<<$ http://www.mct.gov.br/upd_blob/0012/12425.pdf>>. Acesso em 21/07/2015

NORMAN, W.; MACDONALD, C. Getting to the Bottom of "Triple Bottom Line”,Business Ethics Quarterly, v. 14, n.2, pp. 243, 2004.

ORO, I. M.; RENNER, S.; BRAUN, M. Informações de Natureza Socioambiental: Análise dos Balanços Sociais das Empresas Integrantes do Índice de Sustentabilidade Empresarial da Bm\&fBovespa. Revista de Administração da UFSM, 6, edição especial, pp. 879-893, 2013.

PLANTINGA, A.; SCHOLTENS, B. Socially Responsible Investing and Management style of Mutual Funds in the Euronext Stock Markets. Groningen University Working Paper, 2001.

PÓVOA, A.; Valuation: como precificar ações. Rio de Janeiro: Elsevier, 2012;

REIS, E. M., MOREIRA, M. A. e FRANÇA, R. S., Investimento em Meio Ambiente e o Desempenho Econômico das Empresas Aderidas ao Índice Carbono Eficiente - ICO2.Revista de Educação e Pesquisa em Contabilidade, v. 7, n. 4, p. 372-386, 2013. 
ROSS, Stephen A.; WESTERFIELD, Randolph W. e JAFFE, Jeffrey F.; Administração Financeira: Corporate Finance. São Paulo: Atlas, $2^{a}$ edição, 2008;

SÁNCHEZ, J; SOTORRÍO, L. Performance of European SRI Funds vs Conventional Funds. Revista AECA, v.83, p.1-16, 2005.

SCHRÖDER, M. Is there a Difference? The Performance Characteristics of SRI Equity Indexes. ZEW Centre for European Economic Research Paper, v. 5, 2005.

SHARPE, W. F., Capital Asset Prices: a Theory of Market Equilibrium under Conditions of Risk, Journal of Finance, v. 19, n. 3, p. 425-442, 1964.

SOARES, R.O; ROSTGANO, L.M; SOARES, K.T.C. Estudo de evento: o método e as formas de cálculo do retorno anormal. In: Encontro Nacional dos Programas de Pós-Graduação em Administração, 26. Anais. Salvador, 2002.

STATMAN, M. Socially Responsible Mutual Funds. Canyon University Working Paper, 2000.

TEIXEIRA, E. A., NOSSA, V. , FUNCHAL, B. O Índice de Sustentabilidade Empresarial (ISE) e os Impactos no Endividamento e na Percepção de Risco, Revista de Contabilidade Financeira, v.22, n.55, pp. 29-44, 2011.

UNITED NATIONS. (1992) Agenda 21, New York: United Nations Division for Sustainable Development.

VIVIANI, S.; MOURA, G. D.; MACÊDO, F. F. R. R.; SILVA, T. P. A evidenciação ambiental e os indicadores de desempenho ambiental empresarial de companhias abertas participantes do Índice Carbono Eficiente (ICO2). Revista de Gestão Social e Ambiental, v. 8, n. 2, p. 18-35, 2014.

WODD, D. J. "Corporate Social Performance Revisited". Academy of Management Review, v. 16, n. 4, pp. 691-718, 1991. 